\title{
Exploring the functional implications of brain architecture and connectivity: a multi-simulator framework for biophysical neuronal models
}

\author{
Thomas G Close ${ }^{1 *}$, Ivan Raikov ${ }^{1,2}$, Mario Negrello', Shyam Kumar ${ }^{1,2}$, Erik De Schutter ${ }^{1,2}$ \\ From Twenty First Annual Computational Neuroscience Meeting: CNS*2012 \\ Decatur, GA, USA. 21-26 July 2012
}

We introduce a framework for implementing networks of neuronal models with conductance-based mechanisms and morphology (where applicable) across multiple simulators. The framework extends the existing NINEML language [1] by adding two independent modules, NINEML-Conductance and NINEML-BREP [2], which allow the specification of conductance-based mechanisms and geometrically derived connectivity respectively. The PyNN API [3] is utilised to reproduce connectivity across multiple simulators, with adapters added where necessary to accommodate the proposed extensions to NINEML.
PyNN was chosen to handle the multi-simulator connectivity because it offers translations to a wide range of neural simulators and provides a standardised Python interface for simulation control. It is also straightforward to load predefined connectivity into the PyNN-Connector API from a sparse-matrix-like format, allowing a general interface to NINEML-BREP.

Neuronal mechanisms are precompiled into simulator-dependent formats from the NINEML-Conductance declaration, and are then integrated into PyNN via a novel "conductance standard model" class.

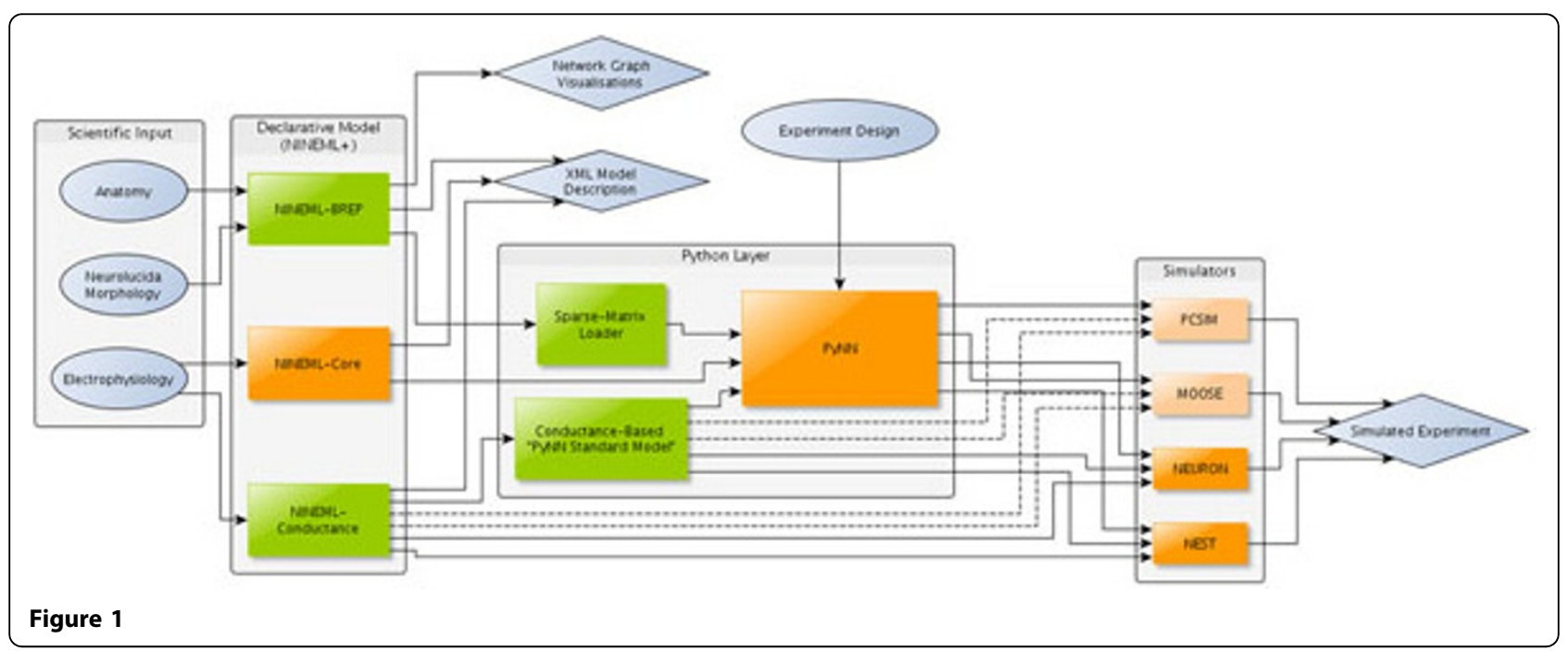

\footnotetext{
* Correspondence: tclose@oist.jp

${ }^{1}$ Computational Neuroscience Unit, Okinawa Institute of Science and

Technology, Okinawa, Japan

Full list of author information is available at the end of the article
}

(c) 2012 Close et al; licensee BioMed Central Ltd. This is an Open Access article distributed under the terms of the Creative Commons 
Depending on whether the selected simulator supports multi-compartment neuronal models, cell morphology is optionally loaded from the NINEML-BREP description and incorporated into the conductance standard model, with flags set in the declarative model description to handle the required adjustments to mechanism parameters.

By the meeting we aim to have completed the extensions to the NINEML language and the required interface between the extended NINEML language and PyNN for the NEURON [4] and NEST [5] simulators, and have a working network model of the cerebellar cortex within this framework. This will enable us to test the effect of varying the biophysical detail of neuronal models and different simulators on the proposed cerebellar cortex model.

\section{Author details}

${ }^{1}$ Computational Neuroscience Unit, Okinawa Institute of Science and Technology, Okinawa, Japan. ${ }^{2}$ University of Antwerp, Antwerp, Belgium.

Published: 16 July 2012

\section{References}

1. NINEML. [http://software.incf.org/software/NINEML].

2. Negrello M, Raikov I, De Schutter E: Boundary representation of neural architecture and connectivity. BMC Neurosci 2011, 12(Suppl 1):59.

3. Davison AP, Brüderle D, Eppler JM, Kremkow J, Muller E, Pecevski DA, Perrinet L, Yger P: PyNN: a common interface for neuronal network simulators. Front. Neuroinform 2008, 2:11.

4. Carnevale NT, Hines ML: The NEURON Book. Cambridge Univ Pr; 2006.

5. Gewaltig M-O, Diesmann M: NEST (Neural Simulation Tool). Scholarpedia 2007, 2(4):1430.

\section{doi:10.1186/1471-2202-13-S1-P150}

Cite this article as: Close et al:: Exploring the functional implications of brain architecture and connectivity: a multi-simulator framework for biophysical neuronal models. BMC Neuroscience 2012 13(Suppl 1):P150.

\section{Submit your next manuscript to BioMed Central} and take full advantage of:

- Convenient online submission

- Thorough peer review

- No space constraints or color figure charges

- Immediate publication on acceptance

- Inclusion in PubMed, CAS, Scopus and Google Scholar

- Research which is freely available for redistribution

Submit your manuscript at www.biomedcentral.com/submit
C Biomed Central 